\title{
Formulation and Characterization of Floating Gelucire Matrices of Metoprolol Succinate
}

\author{
Praneeth Kumar Siripuram, Suresh Bandari*, Raju Jukanti, \\ and Prabhakar Reddy Veerareddy \\ Department of Pharmaceutics and Industrial Pharmacy, St. Peter's Institute of \\ Pharmaceutical Sciences, Hanamkonda, Andhra Pradesh, India
}

\begin{abstract}
The aim of the current investigation was to formulate floating sustained-release matrices of metoprolol succinate using Gelucire $43 / 01$ and Gelucire $44 / 14$ by a melt-solidification technique. The in vitro and in vivo characteristics of the prepared matrices were evaluated. The in vitro drug release studies performed in $0.1 \mathrm{~N} \mathrm{HCl}$ revealed a proportional increase in drug release pattern with increased concentration of Gelucire 44/14.

Drug release data were analyzed by various mathematical models, and the mean dissolution time, Dissolution Efficiency, and similarity factor $\left(f_{2}\right)$ were determined in optimizing formulations. Differential scanning calorimetry and Fourier transform infrared spectroscopy showed no chemical interaction between drug and carriers studied. The in vitro floating characteristics of Gelucire matrices were greater than $12 \mathrm{~h}$ with good in vivo gastric retention. The results indicate that Gelucire 43/01 is an appropriate carrier for the development of sustained-release floating drug delivery systems and Gelucire 44/14, a highly hydrophilic and lipophilic balance (HLB) excipient, acts as release enhancer in the formulations studied.
\end{abstract}

\section{INTRODUCTION}

N umerous oral delivery systems have been developed to act as drug reservoirs from which the active substance can be released over a defined period of time at a predetermined and controlled rate (1). A unique problem with conventional sustained-release formulations is the inability to increase their retention time in the stomach and proximal portions of small intestine. Floating drug delivery systems prolong the retention time of a dosage form in the stomach and are useful for absorption window drugs, thereby improving the oral bioavailability of the drug (2-5).

Metoprolol succinate (MS) is a selective, beta-adrenergic receptor blocker that is used in the treatment of hypertension and angina. It has a half-life of 3-7 h (6) and is absorbed from the gastrointestinal tract (7). Metoprolol absorption in the duodenum and jejunum is directly proportional to dose availability (8).

Gelucires are mixtures of mono-, di-, and triglycerides with polyethylene glycol esters of fatty acids. They are inert, semisolid, waxy amphiphilic excipients that are widely used in controlled-release matrices (9) for improvement of the physicochemical properties of drug. Gelucires are characterized by a wide range of melting points, from about $33^{\circ} \mathrm{C}$ to about $65^{\circ} \mathrm{C}$, and by a variety of hydrophilic and lipophilic balance (HLB) values of approximately 1-18 $(10,11)$. Gelucires with low HLB can be employed to decrease the dissolution rate of drugs, and

${ }^{*}$ Corresponding author. ones with high HLB for fast release $(12,13)$. The advantages of Gelucires over polymers in the design of controlled drug delivery systems include (1) low melt viscosity, obviating the need for solvents; (2) absence of toxic impurities; (3) potential for biocompatibility and biodegradability; and (4) prevention of gastric irritation by forming a coating around the drug $(14,15)$.

Gelucire 43/01 is a highly hydrophobic lipid with an HLB value of 1 and a melting point of $43^{\circ} \mathrm{C}$. The extreme hydrophobicity of Gelucire 43/01 provides release-retarding properties and floating behavior (16). Gelucire 44/14 is a semi-solid excipient with an HLB value of 14 and a melting point at $44^{\circ} \mathrm{C}$. The hydrophilic property of Gelucire 44/14 is useful in dissolution enhancement as well as in controlled-release formulations (17).

The main objective of the present investigation was to formulate floating sustained-release matrices using a melt-solidification method and to evaluate their in vitro and in vivo characteristics.

\section{MATERIALS AND METHODS \\ Materials}

Metoprolol succinate was a kind gift from Dr. Reddy's Laboratories (Hyderabad, India). Gelucire 43/01 (lot no. 4E4706-2) and Gelucire 44/14 (lot no.102699) were generous gift samples from Gattefosse (St Priest, Cedex, France). Seloken XL tablets (lot no. SXHJ001, AstraZeneca, India) is an innovator reference product purchased from the local market. All other chemicals were of analytical grade. 
Table 1. Composition of Metoprolol Succinate-Gelucire Matrices

\begin{tabular}{lccc}
\hline Formulations & $\begin{array}{l}\text { Metoprolol } \\
\text { Succinate (mg) }\end{array}$ & $\begin{array}{l}\text { Gelucire } \\
\mathbf{4 3 / 0 1}(\mathbf{m g})\end{array}$ & $\begin{array}{l}\text { Gelucire } \\
\mathbf{4 4 / 1 4}(\mathbf{m g})\end{array}$ \\
\hline F1 & 95 & 95 & - \\
\hline F2 & 95 & 190 & - \\
\hline F3 & 95 & 285 & - \\
\hline F4 & 95 & 142.5 & 47.5 \\
\hline F5 & 95 & 133 & 57 \\
\hline F6 & 95 & 114 & 76 \\
\hline F7 & 95 & 95 & 95 \\
\hline F8 & 95 & 213.75 & 71.25 \\
\hline F9 & 95 & 199.5 & 85.5 \\
\hline F10 & 95 & 171 & 114 \\
\hline F11 & 95 & 142.5 & 142.5 \\
\hline
\end{tabular}

\section{Methods}

Preparation of Matrices

The desired amounts of the Gelucire in each

formulation were melted at $60^{\circ} \mathrm{C}$ in glass beakers. The calculated amount of metoprolol succinate (MS) was added to the molten vehicle with continuous stirring at $100 \pm 10 \mathrm{rpm}$. The homogenous mixture was then poured into an injector and volumetrically filled into size 0 , hard gelatin capsules and allowed to solidify at $4^{\circ} \mathrm{C}$. The capsules were equilibrated to room temperature for $6 \mathrm{~h}$ before evaluation. The compositions of MS Gelucire matrices are shown in Table 1.

\section{Drug Content}

The method used for drug content estimation is found in the literature (18). Gelucire matrices equivalent to the dose of MS were added to $100 \mathrm{~mL}$ of $0.1 \mathrm{~N} \mathrm{HCl}$, heated to $60^{\circ} \mathrm{C}$, and allowed to cool to room temperature. Upon cooling, the Gelucire solidified, and the drug in $0.1 \mathrm{~N} \mathrm{HCl}$ was filtered through a $0.45-\mu \mathrm{m}$ membrane filter. Filtrate samples were suitably diluted, and the drug content was estimated by UV spectrophotometry at $274 \mathrm{~nm}$.

\section{In Vitro Floating Ability}

The in vitro floating ability of the matrices was determined by using USP Apparatus 2 at $50 \mathrm{rpm}$ in $900 \mathrm{~mL}$ of $0.1 \mathrm{~N} \mathrm{HCl}$ maintained at $37 \pm 0.5^{\circ} \mathrm{C}$. The matrices were placed in the medium, and the floating times were measured by visual observation (19).

\section{In Vitro Release Studies}

The in vitro release studies of developed matrices and reference product were carried out in $900 \mathrm{~mL}$ of $0.1 \mathrm{~N} \mathrm{HCl}$ maintained at $37 \pm 0.5^{\circ} \mathrm{C}, 50 \mathrm{rpm}$ using USP Apparatus 2 . Samples were withdrawn at predetermined intervals and analyzed for drug content by UV spectrophotometry at $274 \mathrm{~nm}$.

\section{Analysis of In Vitro Drug Release Data}

The drug release data of formulations were fitted to different kinetic models (zero-order, first-order, Higuchi, and Korsmeyer-Peppas) to evaluate the kinetics of drug release from the matrices (20-24).

Dissolution efficiency (DE) (25) and the time to release $50 \%$ of drug $\left(t_{50 \%}\right)$ were used to compare the results of dissolution tests of different formulations.

$$
\mathrm{DE}_{8} \%=\frac{\int_{0}^{t} y d t}{y 100^{t}} \times 100
$$

$D E$ is defined as the area under the dissolution curve up to time $t$ expressed as a percentage of the rectangle described by $100 \%$ dissolution in the same time where $y_{t}$ is the percentage of drug dissolved at any time $t, y_{100}$ denotes $100 \%$ dissolution, and the integral represents the area under dissolution curve between time zero and $t$. Time $t$ in this study was $8 \mathrm{~h}$.

Another dissolution parameter, mean dissolution time (MDT), which is a measure of the rate of the dissolution process, was calculated using eq 2

$$
\mathrm{MDT}=\frac{\sum_{i=l}^{i=n} t_{\text {mid }} \times \Delta M}{\sum_{i=l}^{i=n} \Delta M}
$$

where $i$ is the dissolution sample number, $n$ is the number of observations, $t_{\text {mid }}$ is the midpoint time between $i$ and $i-1$, and $\Delta M$ is the additional amount of drug dissolved between $i$ and $i-1$ (26). As the MDT increases, the drug release rate decreases.

The mean in vitro drug release data was used to calculate the similarity factor $\left(f_{2}\right)$ as recommended by Moore and Flanner (27). The mean dissolution data of Seloken $\mathrm{XL}$ were taken as the reference profile. A value of $f_{2}$ between 50 and $100(28)$ indicates similarity between two profiles.

\section{Statistical Analysis}

The calculated dissolution parameters (MDT, $\mathrm{DE}_{8} \%$, and $\left.t_{50 \%}\right)$ of Gelucire formulations (F4-F11) were compared statistically with those of the reference product (Seloken $\mathrm{XL}$ ). The data were tested by the Student's $t$-test using Instant Graphpad Prism Software and were considered statistically significant at $p<0.05$.

\section{Differential Scanning Calorimetry (DSC)}

Thermograms were recorded for MS, Gelucire 43/01, Gelucire 44/14, and the optimized formulation using a differential scanning calorimeter (Perkin-Elmer, Shelton, CT, USA). Accurately weighed (3.036 mg) samples were placed 
on aluminum plates, sealed with aluminum lids, and heated at a constant rate of $5^{\circ} \mathrm{C} / \mathrm{min}$ over a temperature range of $0-400^{\circ} \mathrm{C}$.

\section{Fourier Transform Infrared Spectroscopy (FTIR)}

FTIR spectra of the MS, Gelucire 43/01, Gelucire 44/14, and optimized formulation were recorded using a Fourier transform infrared spectrophotometer (JASCO V5300 FT-IR, Tokyo Japan). Samples were prepared as $\mathrm{KBr}$ disks using a hydraulic pellet press and scanned from 4000 to $400 \mathrm{~cm}^{-1}$.

\section{In Vivo Radiographic Studies}

The in vivo floating ability of matrices was studied by radiography in three healthy human male volunteers aged 25-30 years and $55-65 \mathrm{~kg}$ body weight. Barium sulfate was uniformly mixed with the molten placebo formulations and solidified at $4{ }^{\circ} \mathrm{C}$. The formulations were volumetrically filled into the capsules. The volunteers were asked to swallow these capsules with $200 \mathrm{~mL}$ of water in the morning. The position of the formulation was visualized by X-ray photographs at intervals of $0.5,1,2,3,4$, and $6 \mathrm{~h}(29,30)$. A local human ethical committee approved the study protocol.

\section{RESULTS AND DISCUSSION}

The drug content of the Gelucire matrices was in the range of $97.9-102.2 \%(w / w)$ indicating good content uniformity of prepared matrices. The initial formulations prepared in ratios of $1: 1,1: 2$, and 1:3 drug-Gelucire 40/13 (F1-F3) exhibited excellent in vitro floating characteristics with zero lag time as reported (16). However the Gelucire matrices prepared in a 1:1 drug-Gelucire ratio did not showed the uniform blend of drug and Gelucire in the molten state. Therefore, drug-Gelucire 43/01 ratios of 1:2 and 1:3 were selected as the basic formulation ratios for further studies. The in vitro floating ability of formulations (F4-F11) with Geluire 43/01 and various concentrations of Gelucire 44/14 affected the floating property of matrices. The matrices of Gelucire 44/14 alone showed nonfloating properties (data not shown). As the amount of Gelucire $44 / 14$ increased beyond $30 \%$ in both ratios (1:2 and 1:3), the matrices did not showed the desired floating characteristics. This may be due to variations in the density of Gelucire 44/14 compared with Gelucire 43/01. However, matrices with Gelucire 44/14 at concentrations below 30\% showed floating properties for $12 \mathrm{~h}$ with zero lag time.

The drug release studies revealed that matrices of Gelucire 43/01 alone showed high retardation of drug release in $0.1 \mathrm{~N} \mathrm{HCl}$. As the amount of Gelucire 43/01 in the formulations increased, the release rate decreased (Figure 1). The MS release from formulations F1, F2, and F3 was about $61.91 \%, 34.24 \%$, and $24.30 \%$, respectively, indicating a decrease in drug release with an increase in Gelucire 43/01 content.

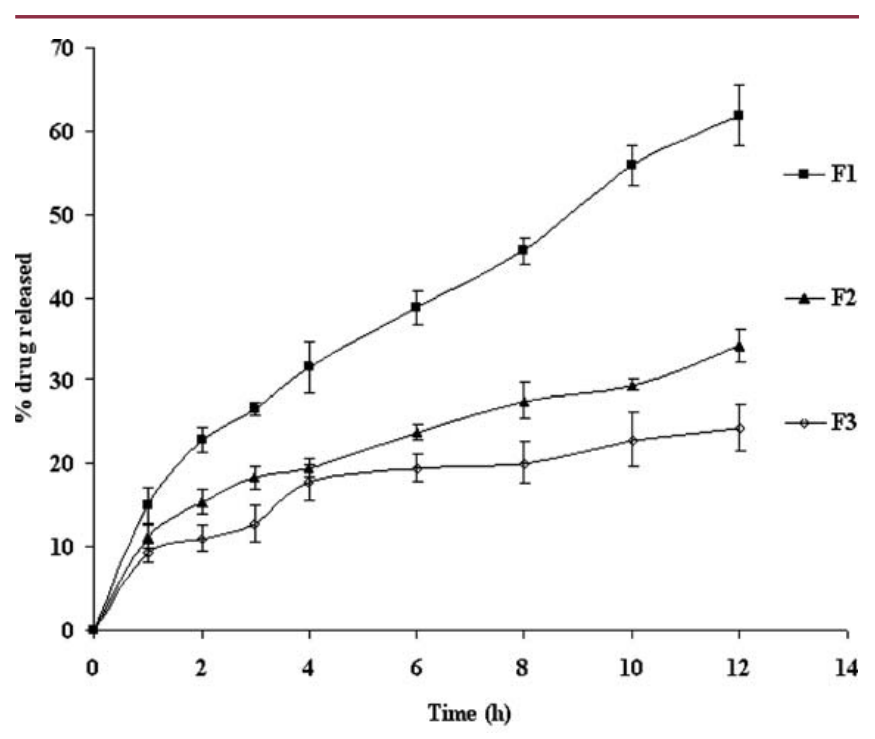

Figure 1. Release profiles of metoprolol succinate from the matrices showing the increasing effect of the Gelucire43/01 ratios. Data represent mean $\pm S D$, $n=3$.

Figure 2 shows MS release from reference product and matrices of 1:2 and 1:3 drug-Gelucire 43/01 with various concentrations of Gelucire 44/14. It indicates that as the proportion of Gelucire 44/14 in the formulation increased, the release increased for both ratios studied. Slow drug release was observed for formulations having high amounts of Gelucire 43/01. This is due to the hydrophobic nature of Gelucire 43/01, which might have reduced the wetting of drug and thus the dissolution.

The dissolution kinetic parameters of the different formulations are presented in Table 2. It is evident from the results that the regression coefficient value

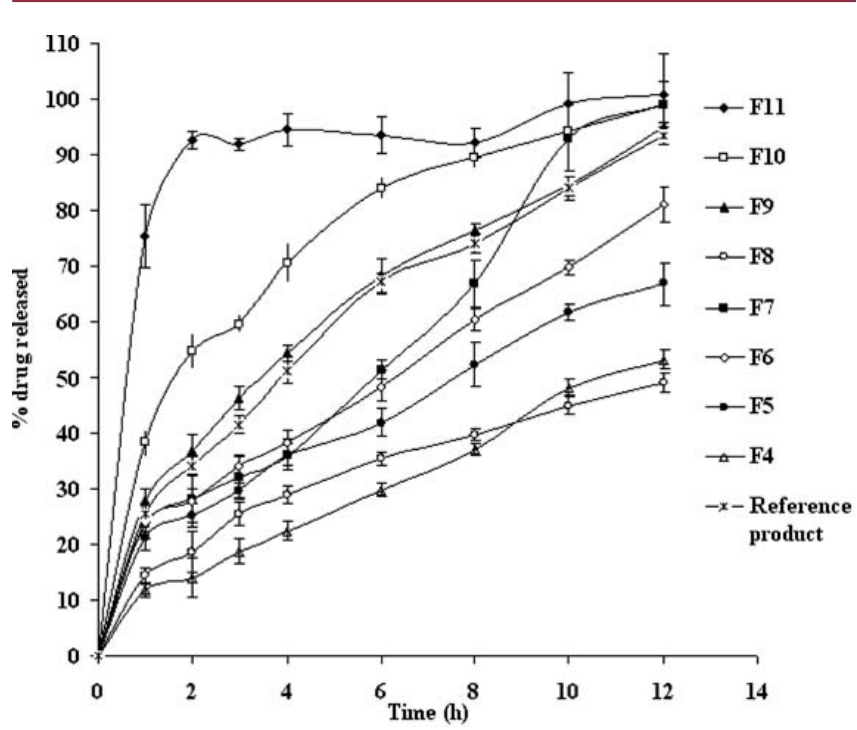

Figure 2. Release profiles of metoprolol succinate from the matrices showing the increasing effect of Gelucire44/14 with Gelucire43/01 and reference product. Data represent mean $\pm S D, n=3$. 
Table 2. In Vitro Release Kinetics of Metoprolol SuccinateGelucire Matrices

\begin{tabular}{|c|c|c|c|c|}
\hline Formulations & $k_{0}\left(\mathrm{mg} \mathrm{h}^{-1}\right)$ & $k_{1}\left(h^{-1}\right)$ & $k\left(\mathrm{mg} \mathrm{h}^{-1 / 2}\right)$ & $n$ \\
\hline F4 & 4.157 & 0.060 & 15.43 & 0.643 \\
\hline F5 & 4.913 & 0.085 & 18.99 & 0.487 \\
\hline F6 & 5.890 & 0.123 & 22.47 & 0.506 \\
\hline F7 & 7.798 & 0.328 & 28.61 & 0.596 \\
\hline F8 & 3.596 & 0.051 & 14.17 & 0.661 \\
\hline F9 & 6.950 & 0.219 & 27.29 & 0.503 \\
\hline F10 & 6.796 & 0.326 & 28.26 & 0.522 \\
\hline $\mathrm{F} 11$ & 7.181 & 0.368 & 29.52 & 0.656 \\
\hline Reference product & 6.999 & 0.203 & 27.22 & 0.487 \\
\hline $\begin{array}{ll}k_{0}: & \text { zero-order rat } \\
k_{1}: & \text { first-order con } \\
k: & \text { Higuchi const } \\
n: & \text { Peppas releas }\end{array}$ & $\begin{array}{l}\text { onstant } \\
\text { ant } \\
\text { t } \\
\text { exponent }\end{array}$ & & & \\
\hline
\end{tabular}

of first-order plot was closer to unity for most of the formulations. Therefore it was ascertained that drug release from the formulations followed first-order kinetics. Further, the data fit to Higuchi and Krosmeyer plots revealed a linear graph with regression value close to one indicating the release from matrix was through a diffusion mechanism. The high regression values $\left(R^{2}\right)$ of the Korsmeyer-Peppas model with release exponent ( $n$ values) between 0.45 and 0.89 suggest that drug release from the

Table 3. Comparison of Dissolution Parameters of Metoprolol Succinate-Gelucire Matrices and Reference Product

\begin{tabular}{lcccc}
\hline Formulations & $\mathbf{M D T}^{a}(\mathbf{h})$ & $\mathbf{D E _ { \mathbf { 8 } } \% ^ { a }}$ & $\boldsymbol{t}_{\mathbf{5 0 \%}}{ }^{a}(\mathbf{h})$ & $\boldsymbol{f}_{\mathbf{2}}$ \\
\hline F4 & $5.22 \pm 0.16$ & $21.75 \pm 2.10$ & $10.50 \pm 0.28$ & 28.88 \\
\hline F5 & $4.39 \pm 0.14$ & $33.30 \pm 1.96$ & $7.55 \pm 0.66$ & 39.84 \\
\hline F6 & $4.12 \pm 0.12$ & $37.58 \pm 1.86$ & $6.16 \pm 0.44$ & 30.09 \\
\hline F7 & $3.95 \pm 0.15$ & $38.41 \pm 2.05$ & $5.95 \pm 0.01$ & 53.63 \\
\hline F8 & $5.09 \pm 0.16$ & $26.47 \pm 2.09$ & $12.62 \pm 0.19$ & 30.09 \\
\hline F9 & $4.20 \pm 0.13$ & $50.12 \pm 1.72$ & $3.52 \pm 0.20$ & 77.3 \\
\hline F10 & $2.96 \pm 0.14$ & $64.57 \pm 1.85$ & $1.89 \pm 0.52$ & 34.82 \\
\hline F11 & $1.36 \pm 0.14$ & $85.14 \pm 2.15$ & $0.58 \pm 0.04$ & 24.38 \\
\hline Reference & $4.27 \pm 0.12$ & $48.32 \pm 1.64$ & $3.69 \pm 0.15$ & - \\
\hline product & & & &
\end{tabular}

${ }^{\mathrm{a}}$ Mean \pm S.D. $(n=3)$

DE: dissolution efficiency

MDT: mean dissolution time

$T_{50 \%}$ : time required for release $50 \%$ of drug

$f_{2}$ : $\quad$ similarity factor matrices followed an anomalous non-Fickian diffusion mechanism.

Drug release profiles of formulations were compared with those of the reference product (Seloken $\mathrm{XL}$ ) to optimize the best formulation using the similarity factor $\left(f_{2}\right)$. The formulation showing an $f_{2}$ value nearest to 100 ranked as the best formulation. The results in Table 3 show that the $f_{2}$ values for formulations $\mathrm{F} 7$ and $\mathrm{F} 9$ are greater than 50 . However, formulation F9 exhibited the highest $f_{2}$ value among all the formulations (77.3) and is thus considered the best formulation.

Additional dissolution parameters such as $\mathrm{MDT}, \mathrm{DE}_{8} \%$, and $t_{50 \%}$ for the reference product were $4.27 \mathrm{~h}, 48.32 \%$, and $3.69 \mathrm{~h}$, respectively. Of all formulations, F9 exhibited similar dissolution parameters to the reference product and was statistically insignificant $(p>0.05)$ in comparison with the reference product, hence batch F9 was considered as the optimized formulation. In 1:2 and 1:3 drug-Gelucire 43/01 formulations, as the proportion of Gelucire 44/14 increased, the release rate increased with a reduction in MDT and $t_{50 \%}$.

DSC thermograms of pure drug, Gelucire 43/01, Gelucire $44 / 14$, and the optimized formulation (F9) are presented in Figure 3. An endothermic peak corresponding to the melting point of pure drug was prominent in the optimized formulation with respect to Gelucire 43/01 and Gelucire 44/14 peaks, which clearly suggests that the drug was present in an unchanged form.

To get evidence of possible chemical interaction of drug with the Gelucires, FTIR analysis was used $(31,32)$. Figure 4 shows the IR spectra of MS, Gelucire 43/01, Gelucire 44/14, and the F9 formulation. Pure drug shows a characteristic peak at $1384 \mathrm{~cm}^{-1}$ that is due to $\mathrm{C}-\mathrm{H}$ deformation of the gem dimethyl group, and the peak at $1242 \mathrm{~cm}^{-1}$ is indicative of C-O stretching in a secondary alcohol. Gelucire 43/01 and Gelucire 44/14 show important bands at 1741 and $1735 \mathrm{~cm}^{-1}$, respectively,

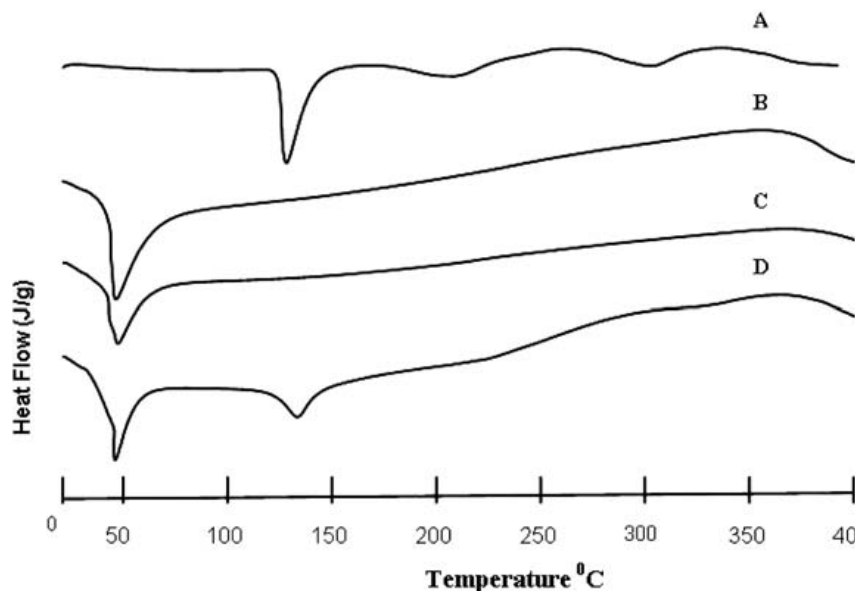

Figure 3. DSC thermograms of (A) metoprolol succinate, (B) Gelucire 43/01, (C) Gelucire 44/14, and (D) optimized formulation (F9). 


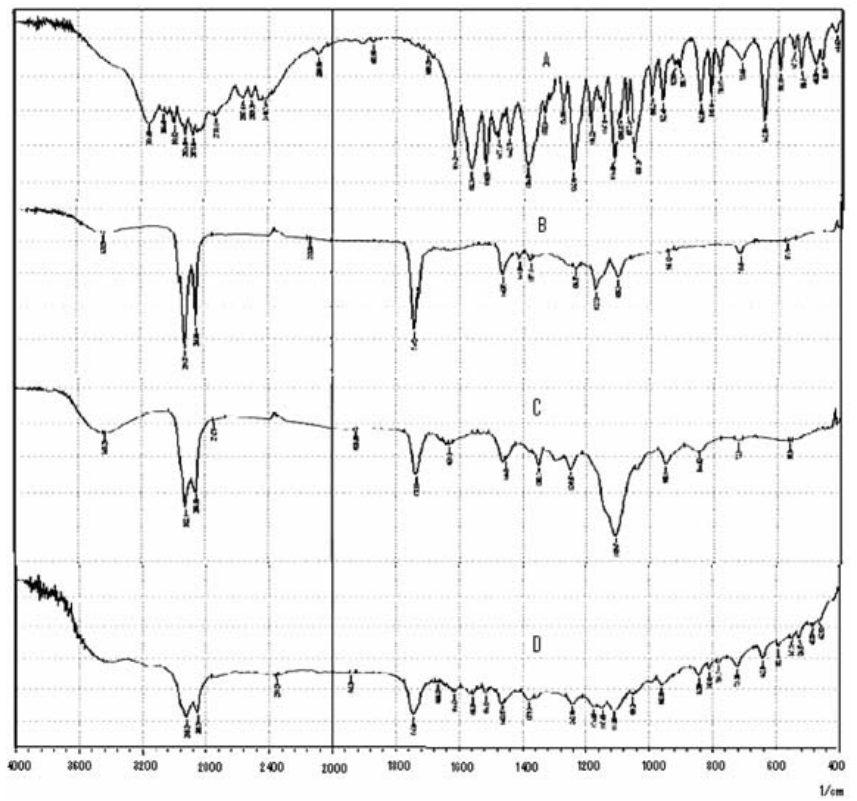

Figure 4. FTIR of (A) metoprolol succinate, (B) Gelucire 43/01, (C) Gelucire $44 / 14$, and (D) optimized formulation (F9).

which are indicative of $\mathrm{C}=\mathrm{O}$ stretching of the ester group. Peaks at 1172 and $1100 \mathrm{~cm}^{-1}$ can be assigned to the $\mathrm{C}-\mathrm{O}$ stretch of alcohols (primary or secondary). The FTIR spectrum of the optimized formulation displays the characteristic peaks of both drug and Gelucires. Overall, there was no alteration in the characteristic peaks of drug and Gelucires suggesting that there was no interaction between the drug and Gelucire.

In vivo radiographic studies of floating matrices show that the formulation remains in the stomach for about $6 \mathrm{~h}$ (Figure 5). This might be due to higher lipid content of the

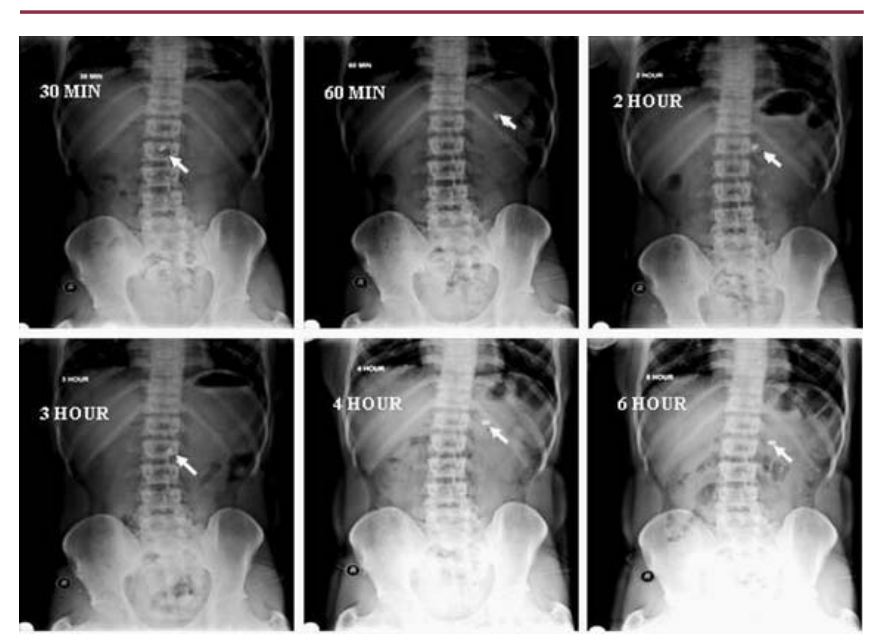

Figure 5. Intragastric behavior of the $\mathrm{BaSO}_{4}$-loaded floating Gelucire matrices represented by typical radiographic images after definite time intervals.

Dissolution Technologies | AUGUST 2010 formulation along with buoyant characteristics of the Gelucires. However, the position of the matrices within the stomach changed with time.

\section{CONCLUSION}

Gelucire 43/01 may be an appropriate carrier for sustained-release floating drug delivery systems because of its extreme hydrophobicity and low density. Gelucire 44/14, a high HLB excipient, acted as a dissolution enhancer in the formulations studied. Developed formulations showed good compatibility between drug and Gelucires and excellent in vitro and in vivo gastric retention indicating successful development of a sustained-release floating drug delivery system.

\section{ACKNOWLEDGMENTS}

Mr. Praneeth is grateful to the All India Council for Technical Education for providing financial support. The authors thank Gattefosse (France) for providing the gift sample of Gelucires and Mr.T. Jayapal Reddy, Director, St.Peter's Institute of Pharmaceutical Sciences, for providing the facilities to carry out this work.

\section{REFERENCES}

1. Moes, A. J. Gastroretentive dosage forms. Crit. Rev. Ther. Drug Carrier Syst. 1993, 10, 143-195.

2. Baumgartner, S.; Kristl, J.; Vrecer, F.; Vodopivec, P.; Zorko, B. Optimization of floating matrix tablets and evaluation of their gastric residence time. Int. J. Pharm. 2000, 195, 125-135.

3. Deshpande, A. A.; Shah, N.H.; Rhodes, C.T.; Malick, W. Development of a novel controlled-release system for gastric retention. Pharm. Res. 1997, 14, 815-819.

4. Singh, B. N.; Kim, K. H. Floating drug delivery systems: an approach to oral controlled drug delivery via gastric retention. J. Control. Release 2000, 63, 235-59.

5. Li, S.; Lin, S.; Daggy, B. P.; Mirchandani, H. L.; Chien Y.W. Effect of HPMC and carbopol on the release and floating properties of Gastric Floating Drug Delivery System using factorial design. Int. J. Pharm. 2003, 253, 13-22.

6. Wikstrand, J.; Andersson, B.; Kendall, M.; Stanbrook, H.; Klibaner, M. Pharmacokinetic considerations of formulation: extended- release metoprolol succinate in the treatment of heart failure. J. Cardiovasc. Pharmacol. 2003,41, 151-157.

7. Raimar, L.; Jae Seung, K.; Gordon, L. A. Pharmacokinetics of an immediate release, a controlled release and a two-pulse dosage form in dogs. Eur.J. Pharm. Biopharm. 2000, 60, 17-23.

8. Jobin, G.; Cortot, A.; Godbillon, J. Investigation of drug absorption from gastrointestinal tract of man, I: metoprolol in stomach, duodenum, and jejunum. Br. J. Clin. Pharmacol. 1985, 21, 97S-105S.

9. Mournicout, A. M.; Gerbaud, D.; Brossard, C.; Lefort des Ylouses, D. Gélules á matrices semi-solide de gélucire-Lyodisponibilité et etude structurale.STP Pharma. Sci. 1990, 6, 368-375. 
10. Aïnaoui, A.; Vergnaud, J. M. Modelling the plasma drug level with oral controlled release forms with lipidic Gelucire. Int. J. Pharm. 1998, 253, 155-162.

11. Sheu, M.T.; Hsia, A. H. O. Polyglycolized saturated glycerides as carrier and enhancer for drug penetration. Chin. Pharm. J. 2001,53, 107-111.

12. Baykara, T.; Yuksel, N. The preparation of prolonged action formulations in the form of semi solid matrix into hard gelatin capsules I.Thermocap method.Drug Dev. Ind. Pharm. 1991, 17, 1215-1227.

13. San Vicente, A.; Hernández, R. M.; Gasćon, A. R.; Calvo, M. B.; Pedraz, J. L. Effect of ageing on the release of salbutamol sulfate from lipid matrices. Int. J. Pharm. 2000, 208, 13-21.

14. Bowtle, W. Lipid formulations for oral drug delivery. Pharm. Technol. Eur. 2000, 12, 20-30.

15. Porter, C. J.H.; Charman, W. N. In vitro assessment of oral lipid based formulations. Adv. Drug Deliver. Rev. 2001,50, S127-S147.

16. Chauhan, B.; Shimpi, S.; Mahadik, K. R.; Paradkar, A. Preparation and evaluation of floating risedronate sodium-gelucire ${ }^{\circledR} 43 / 01$ formulations. Drug Dev. Ind. Pharm. 2005, 31, 851-860.

17. Roussin, P.; Laforet, J. P. Investigating semi-solid formulations: Physical characterization and stability study of Gelucire trademark 44/14. Fram. Vestn. 1997, 48, 260-261.

18. Shimpi, S.; Chauhan, B.; Mahadik, K. R.; Paradkar, A. Preparation and Evaluation of Diltiazem Hydrochloride-Gelucire 43/01 Floating Granules Prepared by Melt Granulation. AAPS PharmSciTech 2004, 5 (3) Article 43, 1-6.

19. Iannuccelli, V.; Coppi, G.; Bernabei, M.T.; Cameroni, R. Air compartment multiple-unit system for prolonged gastric residence. Part I. Formulation study. Int. J. Pharm. 1998, 174, 47-54.

20. Gibaldi, M.; Feldman, S. Establishment of sink conditions in dissolution rate determinations: theoretical considerations and application to nondisintegrating dosage forms. J. Pharm. Sci. 1967, 56, 1238-1242.
21. Korsmeyer, R.; Gurny, R.; Doelker, E.; Buri, P.; Peppas N. Mechanisms of solute release from porous hydrophilic polymers. Int. J. Pharm. 1983, 15, 25-35.

22. Higuchi, T. Rate of release of medicaments from ointment bases containing drugs in suspension. J. Pharm. Sci. 1961, 50, 874-875.

23. Higuchi, T. Mechanism of sustained-action medication. J. Pharm. Sci. 1963, 52, 1145-1149.

24. Higuchi, T. Analysis of data on the medicament release from ointments. J. Pharm. Sci. 1962, 51, 802-804.

25. Banakar, U.V. Pharmaceutical Dissolution Testing, 1st ed.; Marcel Dekker: New York, 1992; pp 191-194.

26. Barzegar-Jalali, M.; Maleki, N.; Garjani, A.; Khandar, A. A.; Haji-Hosseinloo, M.; Jabbari, R.; Dastmalchi, S. Enhancement of dissolution rate and antiinflammatory effects of piroxicam using solvent deposition technique. Drug Dev. Ind. Pharm. 2002, 28, 681-686.

27. Moore, J.W.; Flanner, H. H. Mathematical comparison of dissolution profiles. Pharm. Technol. 1996, 20,64-74.

28. Dissolution Testing of Immediate Release Solid Oral Dosage Forms; Guidance for Industry; U.S. Department of Health and Human Services, Food and Drug Administration, U.S. Government Printing Office: Washington, DC, 1997.

29. Machida, Y.; Inouya, K.; Tokumura, T.; Iwata, M.; Nagai, T. Preparation and evaluation of intragastric buoyant preparations. Drug Design Deliv. 1989, 4, 155-161.

30. Muralidhar, N.; Chandra, S.R. G.; Prabhakar, R.V. Formulation and Evaluation of Gastroretentive Dosage Forms of Clarithromycin. AAPS PharmSciTech 2008, 9, 231-237.

31. Damian, F.; Blaton, N.; Naesens, L.; Balzarini, J.; Kinget, R.; Augustinjns, P.; Mooter, G. V.Physicochemical characterization of solid dispersions of the antiviral agent UC-781 with polyethylene glycol 6000 and Gelucire 44/14. Eur. J. Pharm. Sci. 2000, 10, 311-322.

32. Passerini, N.; Perissutti, B.; Moneghini, M.; Voinovich, D.; Albertini, B.; Cavallari, C.; Rodriguez, L. Characterization of carbamazepine-Gelucire 50/13 microparticles prepared by a spray-congealing process using ultrasounds. J. Pharm. Sci. 2002, 91 (3),699-707. 